\title{
BIODEGRADATION OF NAPHTHALENE AND ANTHRACENE BY CHEMO-TACTICALLY ACTIVE RHIZOBACTERIA OF POPULUS DELTOIDES
}

\author{
Sandeep Bisht ${ }^{1}$, Piyush Pandey ${ }^{1}$, Anchal Sood ${ }^{1}$, Shivesh Sharma ${ }^{1}$, N. S. Bisht ${ }^{2}$ \\ ${ }^{1}$ Department of Microbiology, S.B.S (P.G.) Institute of Biomedical Sciences and Research, Balawala, Dehradun, Uttarakhand, \\ India; ${ }^{2}$ Department of Botany, H.N.B. Garhwal University, Pauri Campus, Pauri, Uttarakhand, India. \\ Submitted: December 29, 2009; Returned to authors for corrections: February 01, 2010; Approved: April 26, 2010.
}

\begin{abstract}
Several naphthalene and anthracene degrading bacteria were isolated from rhizosphere of Populus deltoides, which were growing in non-contaminated soil. Among these, four isolates, i.e. Kurthia sp., Micrococcus varians, Deinococcus radiodurans and Bacillus circulans utilized chrysene, benzene, toluene and xylene, in addition to anthracene and naphthalene. Kurthia sp and B. circulans showed positive chemotactic response for naphthalene and anthracene. The mean growth rate constant $(\mathrm{K})$ of isolates were found to increase with successive increase in substrate concentration $(0.5$ to $1.0 \mathrm{mg} / 50 \mathrm{ml})$. B. circulans SBA12 and Kurthia SBA4 degraded $87.5 \%$ and $86.6 \%$ of anthracene while, Kurthia sp. SBA4, B. circulans SBA12, and $M$. varians SBA8 degraded $85.3 \%, 95.8 \%$ and $86.8 \%$ of naphthalene respectively after 6 days of incubation as determined by HPLC analysis.
\end{abstract}

Key words: Biodegradation; Chemotaxis; Anthracene; Naphthalene

\section{INTRODUCTION}

Soil is a valuable resource as it regulates biogeochemical cycles, filters and remediates pollutants and enables food production (4). Presence of polyaromatic hydrocarbons (PAH) in soil has considerable toxicological concern because of their toxigenic, mutagenic and carcinogenic properties (17). PAH are produced during fossil fuel combustion, waste incineration or as by-products of industrial processes including coal gasification, production of aluminum/iron/steel, petroleum refining, and component of wood preservatives, smoke houses and wood stoves (28). The possible fate of PAH in the environment include chemical oxidation, bioaccumulation and adsorption to soil particles, but the principal process for removal of $\mathrm{PAH}$ is thought to be microbial transformation and degradation (8). Biological treatment is well known to be feasible and effective than chemical treatment because microorganisms directly degrade contaminants rather than merely transferring them from one medium to another and employ metabolic degradation pathways that can terminate with benign waste products (e.g. carbon dioxide and water). Also, microbes derive energy necessary to degrade contaminants from the catabolic degradation of contaminants themselves. Because of all these properties, microbes are used in situ to minimize disturbance of the pollutants from contaminated site (11).

Considerable attention has been focused on the potential of microorganisms to remediate soils contaminated with persistent organic pollutants (3). Since PAH are hydrophobic compounds with low solubility in water, they have a tendency to bind with organic matter or soil, limiting their availability to microorganisms. Despite these properties, many bacterial 
strains have been isolated for their ability to transform, degrade and utilize PAH as a source of carbon and energy (15). Bacterial growth in PAH contaminated soils is dominated by the low bioavailability and often long-term persistence of these compounds (26). Significant bacterial communities with ability to degrade PAH in soil play a critical role in biodegradation in spite of their low bioavailability. Microorganisms inoculated into PAH-contaminated soil environments must find and mobilize PAH before degradation and hence motility and chemotaxis are thought to be desired properties (35).

Since associative interactions of plants and microorganisms have come into existence as a result of coevolution, the use of this interaction for bioremediation of soil holds immense possibilities. When a suitable rhizospheric strain is introduced together with a suitable plant, it settles on the root along with indigenous population, thereby enhancing the bioremediation process. In addition, such efficiently rootcolonizing, pollutant-degrading bacteria exploit the growing root system and hence this acts as an injection system to spread the bacteria through soil. Therefore, the present work was designed to study the biodegradation ability of PAH by rhizospheric bacteria isolated from the rhizosphere of Populus deltoides growing in non contaminated site in Garhwal Himalayas, India. Populus was selected as it has several advantages for the purpose of rhizoremediation, including rapid growth rate (3 to $5 \mathrm{~m} /$ year). In addition, they have extended roots which can reach to the water table; therefore, they have the capacity to treat the contaminant with the saturated zone (34).

\section{MATERIALS AND METHODS}

Soil samples were collected from the rhizosphere of Populus deltoides growing in Garhwal region, India (between $30^{\circ} 17^{\prime} \mathrm{N}$ and $30^{\circ} 24^{\prime} \mathrm{N}$ Latitude., $78.0^{\circ} \mathrm{E}$ and $78^{\circ} 6^{\prime} \mathrm{E}$ longitude) from the depths 0-30 cm using an ethanol-disinfected shovel. Root hairs were carefully collected, loose soil was removed by shaking, and then the roots with tightly bound rhizosphere soil were stored in sterile plastic bags. Samples were collected in triplicates and stored at $4^{\circ} \mathrm{C}$ prior to microbiological analysis. Soil samples $(1.0 \mathrm{~g})$ or fine roots with attached rhizosphere soil were suspended in $100 \mathrm{ml}$ sterile water and kept in incubatory shaker (120 rpm) at $27^{\circ} \mathrm{C}$ for $24 \mathrm{~h}$. Following standing for 30 min, serial dilutions of the suspension were prepared in double distilled sterile water up to dilution $10^{-6}$. Total culturable heterotrophs including aerobic PAH degrader were grown by spray plate technique (13) using minimal salt basal medium (MSB) which consisted of $0.7 \mathrm{~g} \mathrm{NH}_{4} \mathrm{NO}_{3} ; 0.1 \mathrm{~g} \mathrm{~K} \mathrm{KPO}_{4} ; 0.1 \mathrm{~g}$ $\mathrm{KH}_{2} \mathrm{PO}_{4} ; 0.05 \mathrm{~g} \mathrm{MgSO} .7 \mathrm{H}_{2} \mathrm{O} ; 0.013 \mathrm{~g} \mathrm{CaCl} 2.2 \mathrm{H}_{2} \mathrm{O} ; 0.0013 \mathrm{~g}$ $\mathrm{FeSO}_{4} 7 \mathrm{H}_{2} \mathrm{O} ; 2 \%$ agar per $100 \mathrm{ml}$ of de-ionized water. Liquid hydrocarbon when used as substrate was provided in vapour phase (21) until mentioned otherwise.

Chemotaxis response of various isolates for PAH was determined by drop assay method (7). Bacterial cells in logarithmic phase of growth were harvested from $40 \mathrm{ml}$ of nutrient broth and resuspended in $12 \mathrm{ml}$ of chemotaxis buffer (100 $\mathrm{mM}$ potassium phosphate [pH 7.0], $20 \mathrm{mM}$ EDTA) to an optical density at $600 \mathrm{~nm}\left(\mathrm{OD}_{600}\right)$ of approximately 0.7 . A small amount of a test attractant i.e. anthracene or naphthalene was added to the center of a Petridish. Formation of a ring of turbidity near the center of the Petridish was recorded as positive chemotactic response. Succinate was utilized as chemo attractant in positive control.

Growth profile of isolates in anthracene or naphthalene amended medium was determined. MSB was supplemented with different concentrations $(0.5,0.8$ and $1.0 \mathrm{mg} / 50 \mathrm{ml})$ of anthracene or naphthalene. The medium was sterilized and inoculated with the test organism and incubated at $27^{\circ} \mathrm{C}(160$ rev/min). Positive control was experimented in parallel comprising dextrose $(2 \%)$ as sole source of carbon. Growth was assessed by measuring $\mathrm{OD}_{600}$ after time interval of $3 \mathrm{~h}$. Mean growth rate $(\mathrm{K})$ was calculated by formula given as:

\section{$\mathbf{K}=3.322 \log \mathbf{Z}_{\mathbf{t}}-\mathbf{Z}_{\mathbf{n}} / \Delta \mathbf{T}$}

Where $\mathrm{K}$ is mean growth rate constant, $\mathrm{Z}_{\mathrm{t}}$ is final growth at time $\mathrm{t}, \mathrm{Z}_{0}$ is initial growth at time 0 and $\Delta \mathrm{T}$ is difference in time. The data were subjected to analysis of variance, and means compared using $t$ - test statistics. 
Residual amount of anthracene and naphthalene was determined by high performance liquid chromatography (HPLC) analysis in culture medium for quantitative estimation of PAH degradation. Cultures of isolates were separately taken in 250-ml Erlenmeyer flasks containing $50 \mathrm{ml}$ of minimal broth amended with $0.075 \mathrm{mM}$ aliquot of naphthalene or anthracene, dissolved in ethyl acetate. Ethyl acetate was evaporated before adding other components of medium. Medium with evaporated ethyl acetate, devoid of hydrocarbons served as negative control and showed no growth. The cultures were incubated at $150 \mathrm{rpm}$ for 6 days in the dark at $27^{\circ} \mathrm{C}$. The contents of each flask were extracted separately using diethyl ether (99.5\%) in a separating funnel by intermittent shaking. The extracted upper organic layer containing residual PAH was filtered through sodium sorbate to remove excess water. Filtered samples were evaporated to dryness at elevated temperature $\left(50-60{ }^{\circ} \mathrm{C}\right)$ in hot air oven and resuspended in $5 \mathrm{ml}$ of methanol (31). The residues were analyzed by HPLC (Shimadzu equipped with $\mathrm{UV}$-Vis detector operating at $254 \mathrm{~nm}$ ). Separation was carried out with a reverse phase $5 \mu \mathrm{m} \mathrm{C}-18$ column (250x 4.6mm). Isocratic mobile phase was acetonitrile and water $(70: 30, \mathrm{v} / \mathrm{v})$ with a flow rate of $1.3 \mathrm{ml} / \mathrm{min}$. Anthracene and naphthalene standard was also analyzed under the same conditions and residual amount of PAH was estimated by calibration curve.

\section{RESULTS AND DISCUSSION}

Sixteen strains with ability to utilize naphthalene and anthracene were isolated from rhizosphere of Populus deltoides, growing in non contaminated soil. Among these, four isolates were found to utilize both anthracene and naphthalene as sole source of carbon. These strains were identified as Kurthia sp. SBA4, Micrococcus varians SBA8, Deinococcus radiodurans SBA6 and Bacillus circulans SBA12. Kuthia sp. SBA4 and D. radiodurans SBA6 tolerated wide range of $\mathrm{NaCl}$ concentration (2.5 to $10 \%$ ) while, $D$. radiodurans SBA6 and $B$. circulans SBA12 were able to grow in the $\mathrm{pH}$ range of 5.0 to 11 . These strains were assessed for their potential to utilize chrysene, benzene, toluene or xylene as sole source of carbon. Kurthia sp. SBA4 and D. radiodurans SBA12 utilized all the hydrocarbons used in the study (Table 1).

Table 1. Growth test on different liquid and solid hydrocarbon

\begin{tabular}{|c|c|c|c|c|c|c|c|}
\hline S. no & Strains & $\mathbf{A n t}^{\mathrm{a}}$ & Nap $^{b}$ & Ben $^{c}$ & Tol $^{d}$ & $\mathrm{Xyl}^{\mathrm{e}}$ & $\mathrm{Chr}^{\mathrm{f}}$ \\
\hline 1 & SBA4 & +++ & +++ & +++ & + & + & +++ \\
\hline 2 & SBA8 & +++ & +++ & +++ & + & - & +++ \\
\hline 3 & SBA6 & +++ & +++ & ++ & - & + & +++ \\
\hline 4 & SBA12 & +++ & +++ & +++ & + & ++ & +++ \\
\hline
\end{tabular}

These isolates were checked for their chemotaxis activity against naphthalene and anthracene. For both anthracene and naphthalene, a positive chemotactic response was observed as formation of closed ring surrounding but not touching the test attractant in Kurthia sp. SBA4 and B. circulans SBA12, thus indicating valuable effect of chemotaxis on biodegradation activity. The response was similar to succinate used as positive control in contrast in negative control no ring was formed.
There was successive increase in mean growth rate constant $(\mathrm{K})$ of all the isolates with respective increase in concentration of substrate. The K value of Kurthia sp. SBA4, M. varians SBA8, D. radiodurans SBA6, B. circulans SBA12 in medium amended with anthracene $(1 \mathrm{mg} / 50 \mathrm{ml})$ was obtained as $0.44,0.48,0.45$ and $0.36 \mathrm{~h}^{-1}$ respectively, which was relatively higher than other concentrations tested. Similar results were obtained for naphthalene $(1 \mathrm{mg} / 50 \mathrm{ml})$ where 
Kurthia sp. SBA4, M. varians SBA8, D. radiodurans SBA6 and $B$. circulans SBA12 had K value of $0.42,0.37,0.44$ and $0.43 \mathrm{~h}^{-1}$ respectively in exponential phase. The mean growth rate of all the isolates was relatively higher in glucose amended medium where it was $0.68,0.65,0.84$ and $0.65 \mathrm{~h}^{-1}$ for Kurthia sp. SBA4, $M$. varians SBA8, $D$. radiodurans SBA6 and $B$. circulans SBA12 as shown (Table 2). The growth profile of all the isolates at varying concentration of naphthalene and anthracene with respect to control are given in Fig. 1- 4. It was invariably observed that the growth profiles of all the isolates at $0.8 \mathrm{mg} / 50 \mathrm{ml}$ of naphthalene and anthracene were almost similar, which resulted in overlapping of respective graphs (Fig. 1-4).

HPLC analysis of neutral exract from PAH amended culture medium revealed the presence of several metabolites that were eluted at different retention time period ranging from 2.5 to 14 minutes. However, the residual concenteration of anthracene or naphthalene was determined by calculating the peak area relative to standard with pure anthracene and naphthalene with retention time of $6.933 \mathrm{~min}$ and $4.039 \mathrm{~min}$ respectively. All the four isolates were found to substantially reduce PAH concentration in medium as estimated by HPLC analysis. Kurthia sp. SBA4, M. varians SBA8, D. radiodurans SBA6 and B. circulans SBA12 resulted in $86.6 \%, 86.6 \%$, $81.8 \%$ and $87.5 \%$ degradation of anthracene (Fig. 5) while $85.3 \%, 86.8 \%, 27.8 \%$ and $95.8 \%$ decrease in naphthalene concenteration (Fig. 6) was observed respectively by these isolates after 6 days.

Table 2. Mean growth rate constant of isolates at varying concentration of substrate

\begin{tabular}{|c|c|c|c|c|c|c|c|}
\hline \multirow[t]{3}{*}{ Isolates } & \multicolumn{3}{|c|}{ Mean growth rate constant $(K) h^{-1}$} & \multirow{2}{*}{\multicolumn{2}{|c|}{$\begin{array}{l}\text { Naphthalene } \\
(\mathrm{mg} / 50 \mathrm{ml})\end{array}$}} & \multirow{3}{*}{$\begin{array}{c}\text { Concentration } \\
1.0\end{array}$} & \multirow{3}{*}{ Control } \\
\hline & \multicolumn{2}{|c|}{$\begin{array}{l}\text { Anthracene } \\
(\mathrm{mg} / 50 \mathrm{ml})\end{array}$} & \multirow{2}{*}{$\begin{array}{c}\text { Concentration } \\
1.0\end{array}$} & & & & \\
\hline & 0.5 & 0.8 & & 0.5 & 0.8 & & \\
\hline Kurthia sp. SBA4 & $0.24 b$ & $0.33 b$ & $0.44 \mathrm{c}$ & $0.29 b$ & $0.33 b$ & $0.42 \mathrm{c}$ & $0.68 \mathrm{a}$ \\
\hline M. varians SBA8 & $0.35 b$ & $0.38 \mathrm{~b}$ & $0.48 \mathrm{c}$ & $0.27 b$ & $0.28 b$ & $0.37 \mathrm{~b}$ & $0.65 \mathrm{a}$ \\
\hline D. radiodurans $\mathrm{SBA} 6$ & $0.33 b$ & $0.36 b$ & $0.45 \mathrm{c}$ & $0.29 b$ & $0.35 b$ & $0.44 \mathrm{c}$ & $0.84 \mathrm{a}$ \\
\hline B. circulans $\mathrm{SBA} 12$ & $0.32 b$ & $0.35 b$ & $0.36 b$ & $0.33 b$ & $0.35 b$ & $0.43 c$ & $0.65 \mathrm{a}$ \\
\hline
\end{tabular}

*Values followed by different letters in row were significantly different $(\mathrm{P}<0.05)$, using $t$ test statistic.

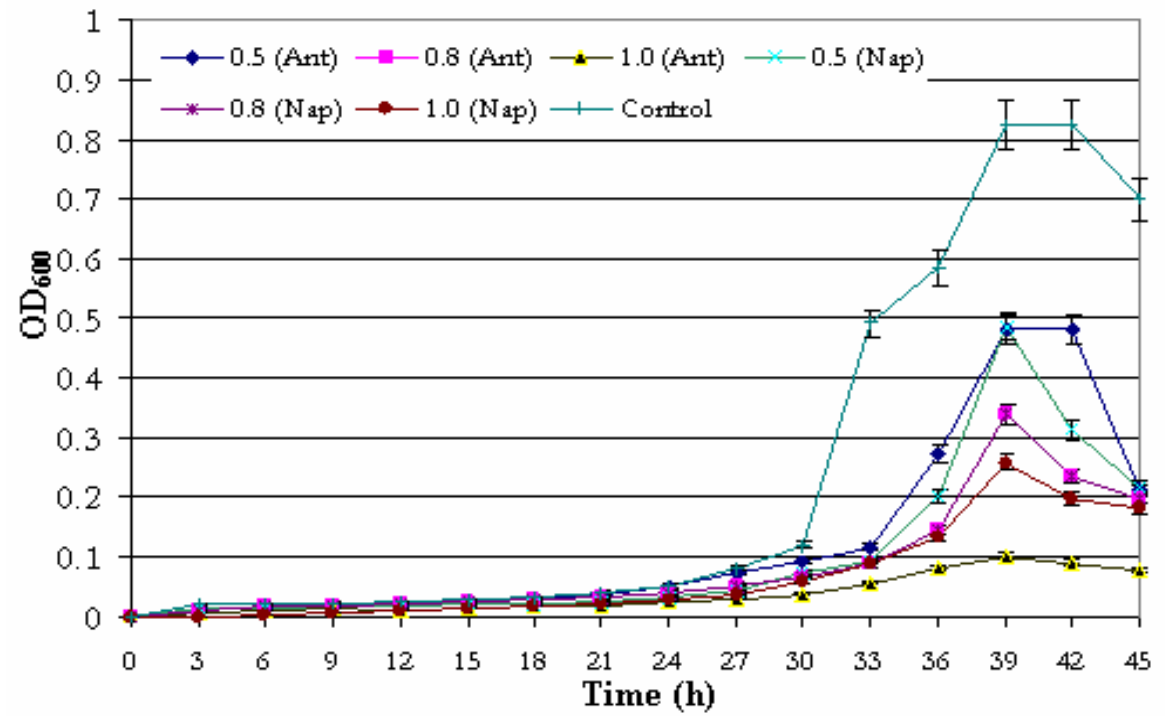

Figure 1. Growth profile of Kurthia sp.SBA4 in medium supplemented with different concentrations of anthracene or naphthalene. Error bars indicate standard error of the mean, where error bars are not visible; they are smaller than the marker. 

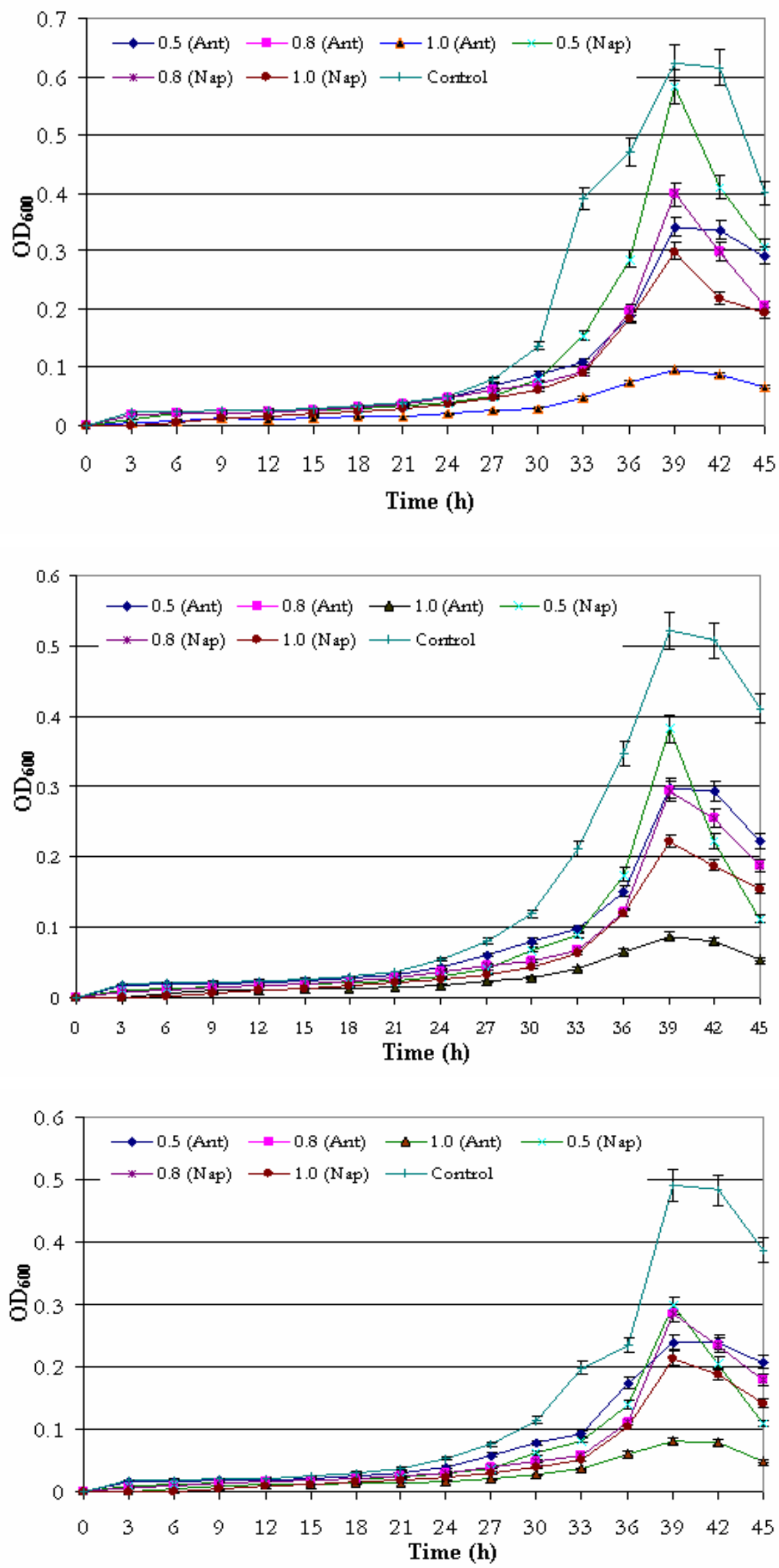

Figure 2. Growth profile of Microccocus varians SBA8 in medium supplemented with different concentrations of anthracene or naphthalene. Error bars indicate standard error of the mean, where error bars are not visible; they are smaller than the marker.

Figure 3. Growth profile of Dienococcus radiodurans SBA6 in medium supplemented with different concentrations of anthracene or naphthalene. Error bars indicate standard error of the mean, where error bars are not visible; they are smaller than the marker.

Figure 4. Growth profile of Bacillus circulans SBA12 in medium supplemented with different concentrations of anthracene or naphthalene. Error bars indicate standard error of the mean, where error bars are not visible; they are smaller than the marker. 


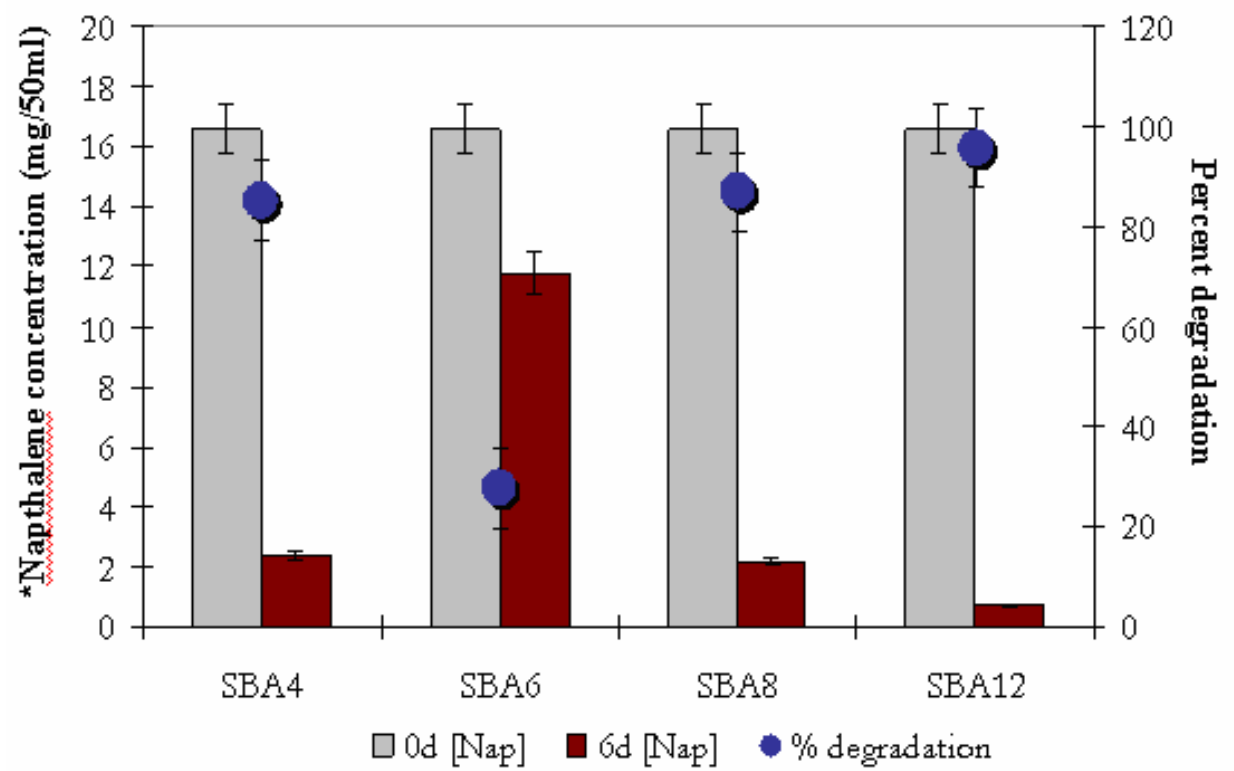

*Napthalene in methanol solvent

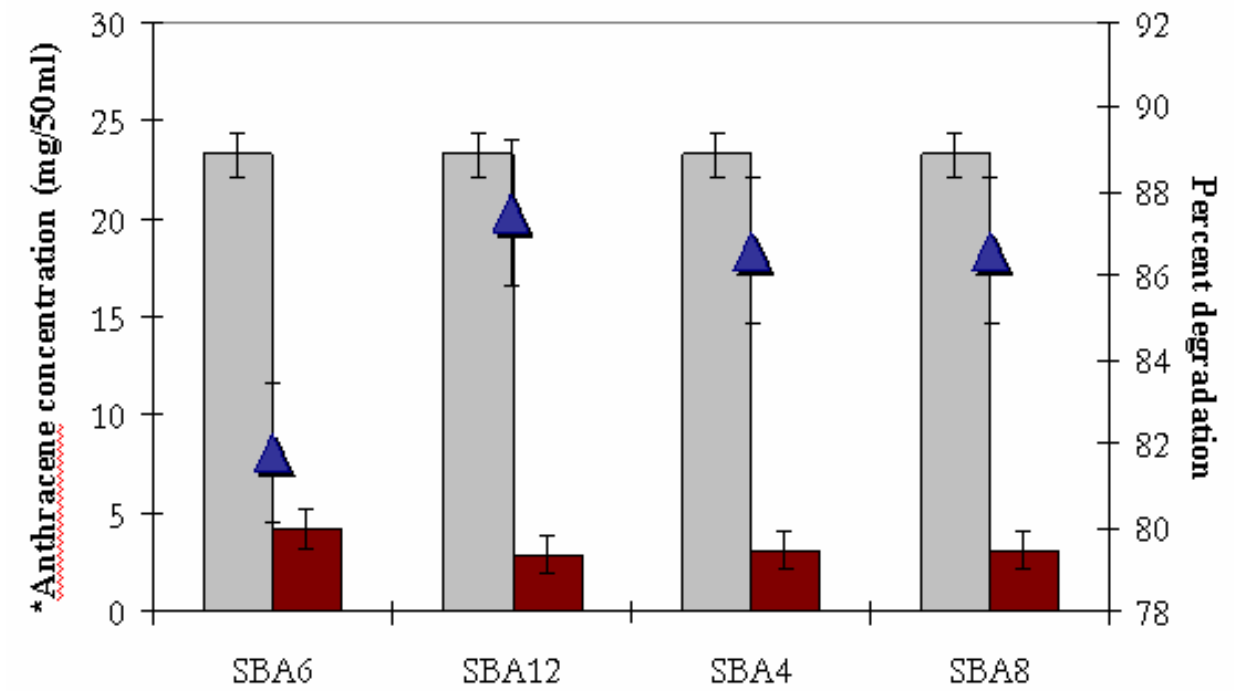

$\square 0 \mathrm{~d}[$ Ant $] \quad \square 6 \mathrm{~d}[$ Ant $] \quad \mathbf{\Delta} \%$ degradation
Figure 5. Degradation of naphthalene by rhizospheric isolates from Populus deltoides estimated by HPLC analysis. Error bars indicate standard error of the mean.

Figure 6. Degradation of anthracene by rhizospheric isolates from Populus deltoides estimated by HPLC analysis. Error bars indicate standard error of the mean.
Kurthia sp. SBA4, M. varians SBA8, D. radiodurans SBA6 and $B$. circulans SBA12 were isolated from the rhizosphere of Populus deltoides with ability to utilize PAH i.e. anthracene and naphthalene along with broad substrate range to utilize other hydrocarbons. These bacteria were isolated from host plant growing in non contaminated soils. Earlier also, Heinonsalo et al. (9) isolated petroleum hydrocarbon degrading bacteria from non-contaminated lignin rich forest humus soils.
In the present study, M. varians SBA8 and D. radiodurans SBA6 were unable to grow on xylene and toluene supplemented medium respectively. The reason might be membrane toxicity and / or absence of necessary enzyme for utilization of these hydrocarbons. As suggested earlier that lipophilic hydrocarbons accumulate in the membrane lipid bilayer, affecting the structural and functional properties of these membranes. The resulting accumulation of hydrocarbon 
molecules leads to membrane loss of integrity, increase in permeability to protons and consequently, dissipation of the proton motive force and impairment of intracellular $\mathrm{pH}$ homeostasis (30).

The findings of this study revealed that rhizosphere of Populus deltoides is associated with increased numbers of PAH degrading bacteria, in spite of absence of these hydrocarbons in situ. Several isolates were capable of utilizing broad range of hydrocarbons thereby making them suitable candidates for rhizoremediation. Similarly, Austrian pine ( $P$. nigra) and willow ( $S$. caprea) trees have been identified as rhizoremediation candidates because of their association with increased numbers of poly chlorinated benzene degraders in the root zone (16). Earlier, isolates from Populus sp. (poplar) and Salix sp. (willow) rhizosphere have been used successfully for rhizoremediation of PHC contaminated soils probably due to introduction of oxygen into deeper soil layers through specialized root vessels and aerenchyma (37).

In fact, PAH degrading organisms and higher degradation rates have been detected in the bulk soil collected from planted treatments than in the bulk soil collected from unplanted treatments in rhizoremediation studies $(18,29)$. These findings are promising indications that certain trees may positively affect the number of degrading microorganisms in a large volume of soil, beyond the immediate vicinity of the roots traditionally defined as the rhizosphere. In accordance to the fact, $P$. deltoides was used in present study as an ideal habitat for degrading organisms, because its rhizosphere provides controlled conditions for symbiotic growth of microorganisms adapted for roots. In fact, its roots provide excellent attachment locations, steady redox conditions, and a steady food supply of exudates consisting of organic acids, enzymes, amino acids, and complex carbohydrates (1). Further, presence of high levels of phenolic compounds in root exudates is known (6) to induce bacterial degradation pathways (27). In this study, four PAH degrading isolates was identified as Kurthia sp. SBA4, M. varians SBA8, D. radiodurans SBA6 and B. circulans SBA12. Earlier also, Micrococcus varians (22) and certain Bacillus species (10) have been identified for PAH degradation, however reports on $\mathrm{PAH}$ degradation by rhizospheric Deinococcus spp. and Kurthia spp. are not well documented. Pertaining to the fact that all four were rhizosphere isolates with PAH degrading abilities, their potential may be exploited for bioremediation as also previously described by coating the rhizobacteria on Barmultra seeds or seedlings (14). In fact, the rhizosphere is a nutrient-rich environment when compared with bulk soil; therefore, it can function as a nutrient source for rhizosphere bacteria during rhizoremediation, making them metabolically more active.

In present study Kurthia sp. SBA4 and B. circulans SBA12 exhibited positive chemotactic response for anthracene and naphthalene. Chemotaxis has been reported to play an important role in enhancing biodegradation as it increases bioavailability of pollutants to bacteria (23). This ability of motile bacteria provides the advantage to locate compounds such as anthracene and naphthalene that support growth of microorganisms. Chemotactic cells would be especially efficient at sensing and swimming towards chemicals that are present at point sources, for example, absorbed to the soil particles, in ground water or within slowly moving pollutants plumes. In this way chemotactic bacteria overcome masstransfer limitations that impede bioremediation processes (24). Grimm and Harwood (7) reported that naphthalene and its degradation pathway intermediate, salicylate, influence behavioral responses in two naphthalene-degrading motile bacteria, P. putida G7 and Pseudomonas sp. strain NCIB 98164. As a matter of fact, the relation between chemotaxis and biodegradation is well established, as a Ralstonia strain was reported earlier to be chemotactic towards different nitro aromatic compounds (NAC) which were subsequently degraded completely by this organism (25). Though, chemotactically active PAH degrading bacteria are known to be present in contaminated soil (7), Kurthia sp. SBA4 and $B$. circulans SBA12 were isolates from non contaminated Populus rhizosphere.

Maximum growth rate of bacterial isolates was recorded when glucose was used as sole source of carbon during growth experiment. The growth rate of four isolates was relatively less 
when anthracene or naphthalene was provided as carbon source. However, successive increase was resulted in increased growth rate of four isolates with substrate concentration (up to $1 \mathrm{mg} / 50 \mathrm{ml})$. This further confirmed that anthracene and naphthalene concentration are significant in growth physiology of the isolates and may also act as limiting nutrients in rhizosphere. Though, it was evident that the substrate concentration only affect the multiplication rate of organisms while the growth profile remained unaffected with successive increased in PAH concentration. Earlier, Juhasz et al. (12) have studied the effect of PAH on growth of Burkholderia cepacia, where growth was evaluated by visual monitoring, while in the present study mean growth rate $(\mathrm{K})$ was determined at various concentration of PAH. However, in present work, the $\mathrm{K}$ values of isolates increased with the increasing substrate concentration, but the biomass decreased with respective increasing concentrations of anthracene or naphthalene. This might be attributed to membrane toxicity of PAH substrates at higher concentrations (30). Nawana et al. (22) studied the growth of Acinetobacter anitratus on chrysene in culture medium for 35 days by total viable count method.

The quantitative estimation of residual amount of PAH in culture medium suggested that more than $85 \%$ of anthracene was degraded by all the four isolates. Similarly, appreciable amount of naphthalene was also removed by the isolates except D. radiodurans SBA6. Interestingly, more than $95 \%$ of naphthalene was removed by $B$. circulans SBA12 which reflects it's excellent bioremediation potential. Earlier also, 92 $\%$ and $90 \%$ removal of anthracene and phenanthrene from cell suspension has been reported with Mycobacterium sp. strain PYR-1 respectively, after 14 days (19). However in the present study similar quantities were removed within 6 days only. Earlier, degradation of PAH in liquid medium by Pseudomonas sp. strain $8909 \mathrm{~N}$ (20) and Mycobacterium sp. strain LB501T (36), have been reported, associated with formation of biofilm on substrate.

Conclusively, isolates Kurthia sp. SBA4, M. varians SBA8, D. radiodurans SBA6 and B. circulans SBA12 have ability to degrade PAH. The study describes the selection of plant-microbe pair to degrade different organic pollutant for bioremediation. The initial results of this study suggest that the isolates Kurthia sp. SBA4, Micrococcus varians SBA8, Deinococcus radiodurans SBA6 and Bacillus circulans SBA12 have promising characteristics for rhizoremediation of $\mathrm{PAH}$ using Populus rhizosphere as inoculation system in soil. Further work is required to assess the potential of this 'plantmicrobe pair' in contaminated sites.

\section{ACKNOWLEDGEMENT}

The authors are grateful to G. B. Pant Institute of Himalayan Environment and Development, Ministry of Environment and Forest, Govt. of India for financial support. The authors are also thankful to Ozone Pharmaceuticals Pvt. Ltd., Haryana, India for HPLC analysis. Involvement and concern of Dr. Anita Pandey, GBPHIED, Kosi, Almora, India, is greatly acknowledged.

\section{REFERENCES}

1. Aprill, W.; Sims, R.C. (1990). Evaluation of the use of prairie grasses for stimulating polycyclic aromatic hydrocarbon treatment in soil. Chemos. 20, 253-265.

2. Belimov, A.A.; Safronova, V.I.; Mimura, T. (2002). Response of spring rape (Brassica napus var. oleifera L.) to inoculation with PGPR containing ACC deaminase depends on nutrient status of plants. Can. J Microbiol. 48, 189-199.

3. Borgardt, A.H; Hemmingsons, B.B. (1992). Enumeration of Phenanthrene degrading bacteria by an overlayer techique and its use in evaluation of petrloeum contaminated sites. App Env Microbiol.58, $2579-2583$.

4. Borneman, J; Austin-Philip, S; Triplett, E.W. (1996). Method development to assess microbial diversity in soil. Bio. cent.

5. Barnard, E.L. (1994). The nursery to field carryover and post outplanting impact of M. phaseolina on loblolly pine on a cutover forest site in North Central Florida. Tree Planter's Notes. 45, 68-71

6. Fletcher, J.S.; Hedge, R.S. (1995). Release of phenols by perennial plant roots and their potential importance in bioremediation. Env. Toxicol Chem. 31, 3009-3016.

7. Grimm, A.C.; Harwood C.S. (1997). Chemotaxis of Pseudomonas sp. to the polyaromatic hydrocarbon naphthalene. Appl. Env. Microbiol. 63, 4111- 4115.

1. Gibson, D.T.; Mahadevan, V.; Jerina, R.M.; Yagi, H.; Yeh, H.J.C. 
(1975). Oxidation of carcinogens benzo [a] pyrene and dibenz [a,h] anthracene to dihydrols by a bacterium. Sci. 189, 295-297.

8. Heinonsalo, J.; Jorgensen, K.S.; Haahtela, K; Sen, R. (2000). Effects of Pinus sylvestris root growth and mycorrhizosphere development on bacterial carbon source utilization and hydrocarbon oxidation in forest and petroleum contaminated soils. Can. J. Microbiol. 46(5), 451-464.

9. Ilori, M.O.N.; Amund, D.L. (2000). Degradation of anthracene by bacteria isolated from oil polluted tropical soils. Z. Naturforsch. 55, 890897.

10. Johnsen, A.R.; Wick, L.Y.; Harms, H. (2005). Principles of microbial PAH-degradation in soil. Env. Poll. 133, 71-84.

11. Juhasz, A.L.; Britz, M.L.; Stanley, G.A. (1997). Degradation of fluoranthene, pyrene, benz $[a]$ anthracene and dibenz $[a, h]$ anthracene by Burkholderia cepacia. J. App. Microbiol. 83, 189-198.

12. Kiyohara, H.; Sugiyama, M.; Mondello, F.J.; Gison, D.T.; Yano, K. (1983). Plasmid involvement in the degradation of polycyclic hydrocarbons by a Beijerinckia species. BBRC. 111, 939-945.

13. Kuiper, I.; Bloemberg, G.V.; Lugtenberg, B.J.J. ( 2001). Selection of a Plant-Bacterium Pair as a novel tool for Rhizostimulation of Polycyclic Aromatic Hydrocarbon-Degrading Bacteria. Ameri. Phytopathol. Soc. 14, 1197-1205.

14. Lee, P.H.; Ong, S.K.; Golchin, J.; Nelson, G.1. (2001). Use of solvent to enhance PAH degradation of col-tar contaminated soils. Wat. Res. 35, 3941- 3945.

15. Leigh, M.B.; Prouzova, P.; Mackova, M.; Macek, T.; Nagle, D.P.; Fletcher, J.S. (2006). Polychlorinated Biphenyl (PCB)-Degrading Bacteria Associated with Trees in a PCB-Contaminated Site. Appl. Env. Microbiol.. 72, 2331-2342

16. Mersch-Sundermann, V.; Mochayedi, S.; Kevekordes, S. (1992). Genotoxicity of polycyclic aromatic hydrocarbons in Escherichia coli PQ37. Mut. Res. 278, 1-9.

17. Miya, R.K.; Firestone, M.K. (2000). Phenanthrene-degrader community dynamics in rhizosphere soil from a common annual grass. J. Env. Qual. 29, 584-592.

18. Moody, J.D.; Freeman, J.P.; Doerge, D.R.; Cerniglia, C.E. (2001). Degradation of Phenanthrene and Anthracene by Cell Suspensions of Mycobacterium sp. Strain PYR-1. Appl. Env. Microbiol. 1476-1483

19. Mulder, H.; Breure, A.D.; van Honschooten, M.; Grotenhuis, J.T.C.; Van Andel, J.G.; Rulkens, W.H. (1998). Effect of biofilm formation by Pseudomonas $8909 \mathrm{~N}$ on the bioavailability of solid naphthalene. Appl. Microbiol. Biotechnol. 50, 277-283.

20. Na, K.S.; Kuroda, A.; Takiguchi, N.; Ikeda, T.; Ohtake, H.; Kato, J. (2005). Isolation and characterization of benzene tolerant Rhodococcus opacus strains. J. Biosci. Bioeng. 99, 378-382.

21. Nwanna, I.E.M.; George, G.O.; Olusoji, I.M. (2006). Growth study on chrysene degraders isolated from polycyclic aromatic hydrocarbon polluted soils in Nigeria. Af. J. Biotechnol. 5, 823-828.

22. Pandey, G.; Jain, R.K. (2002). Bacterial chemotaxis toward environmental pollutants: role in bioremediation. Appl. Env. Microbiol. 68, 5789-5795.

23. Parales, R.E.; Ditty, J.Y.; Harwood, C.S. (2000). Toulene degrading bacteria are chemotactic towards the enviormental pollutants Benzene, Toluene and Trichloroethylene. Appl. Env. Microbiol. 66, 4098-4104.

24. Samanta, S.K.; Bhushan, B.; Chauhan, A.; Jain, R.K. (2000). Chemotaxis of a Ralstonia sp. SJ98 toward different nitroaromatic compounds and their degradation. Biochem. Biophys. Res. Comm. 269, 117-123.

25. Semple, K.T.; Doick, K.J.; Jones, K.C.; Burauel, P.; Craven, A.; Harms, H. (2004). Defining bioavailability and bioaccessibility of contaminated soil and sediment is complicated. Env. Sci. Technol. 38, 228-231.

26. Shurtliff, M.M.; Parkin, G.F.; Weathers, L.J.; Gibson, D.T. (1996). Biotransformation of trichloroethylene by a phenol-induced mixed culture. J. Env. Eng. 122, 581-589.

27. Shuttleworth, K.L.; Cerniglia, C.E. (1995). Environmental aspects of PAH biodegradation. Appl. Biochem. Biotechnol. 54, 291-302.

28. Siciliano, S.D.; Germida, J.J.; Banks, K.; Greer, C.W. (2003). Changes in microbial community composition and function during a polyaromatic hydrocarbon phytoremediation field trial. Appl. Env. Microbiol. 69, 483489.

29. Sikkema, J.; Bont, J.A.; Poolman, B. (1995). Mechanisms of membrane toxicity of hydrocarbons. Microbiology Reviews 59(2), 201-222.

30. Singh, S.; Canda, R.; Patel, D.K.; Rai, V. (2007). Isolation and characterization of novel Serratia marcescens (AY927692) for pentachlorophenol degradation from pulp and paper mil waste. W. J. Microbiol. Biotechnol. 23, 1747-1754.

31. Subba Rao, N.S. (1982). In: Advances in agriculture microbiology; Oxford and IBH Publication Co. 229-305.

34. Shields, M.S.; Francesconi, S.C. (1996). Molecular techniques in bioremediation,

p. 341-390. In R. L. Crawford and D. L. Crawford (ed.), Bioremediation: principles and applications. Cambridge University Press, Cambridge, United Kingdom.

35. Turnbull, G.A.; Morgan, J.A.W.; Whipps, J.M.; Saunders, J.R. (2001). The role of motility in the in vitro attachment of Pseudomonas putida PaW8 to wheat roots. FEMS Microbial Ecol. 35, 57-65.

36. Wick, L.Y.; Colangelo, T.; Harms, H. (2001). Kinetics of mass transfer limited bacterial growth on solid PAHs. Env. Sci. Technol. 35, 354-361.

37. Zalesny, Jr.R.S.; Bauer, E.O.; Hall, R.B.; Zalesny, J.A.; Kunzman, J.; Rog, C.J.; Riemenschneide, D.E. (2005). Clonal variation in survival and growth of hybrid poplar and willow in an in situ trial on soils heavily contaminated with petroleum hydrocarbons. Int. J. Phytorem. 7, 177197. 